\title{
Volcanic ash infrared signature: porous non-spherical ash particle shapes compared to homogeneous spherical ash particles
}

\author{
A. Kylling ${ }^{1}$, M. Kahnert ${ }^{2,3}$, H. Lindqvist ${ }^{4}$, and T. Nousiainen ${ }^{4,5}$ \\ ${ }^{1}$ NILU - Norwegian Institute for Air Research, P.O. Box 100, 2027 Kjeller, Norway \\ ${ }^{2}$ Research Department, Swedish Meteorological and Hydrological Institute, Folkborgsvägen 17, 60176 Norrköping, Sweden \\ ${ }^{3}$ Department of Earth and Space Science, Chalmers University of Technology, 41296 Gothenburg, Sweden \\ ${ }^{4}$ Department of Physics, P.O. Box 48, 00014 University of Helsinki, Helsinki, Finland \\ ${ }^{5}$ Finnish Meteorological Institute, P.O. Box 503, 00101 Helsinki, Finland
}

Correspondence to: A. Kylling (arve.kylling@nilu.no)

Received: 19 August 2013 - Published in Atmos. Meas. Tech. Discuss.: 16 October 2013

Revised: 17 February 2014 - Accepted: 21 February 2014 - Published: 4 April 2014

\begin{abstract}
The reverse absorption technique is often used to detect volcanic ash clouds from thermal infrared satellite measurements. From these measurements effective particle radius and mass loading may be estimated using radiative transfer modelling. The radiative transfer modelling usually assumes that the ash particles are spherical. We calculated thermal infrared optical properties of highly irregular and porous ash particles and compared these with mass- and volume-equivalent spherical models. Furthermore, brightness temperatures pertinent to satellite observing geometry were calculated for the different ash particle shapes. Non-spherical shapes and volume-equivalent spheres were found to produce a detectable ash signal for larger particle sizes than mass-equivalent spheres. The assumption of massequivalent spheres for ash mass loading estimates was found to underestimate mass loading compared to morphologically complex inhomogeneous ash particles. The underestimate increases with the mass loading. For an ash cloud recorded during the Eyjafjallajökull 2010 eruption, the mass-equivalent spheres underestimate the total mass of the ash cloud by approximately $30 \%$ compared to the morphologically complex inhomogeneous particles.
\end{abstract}

\section{Introduction}

The difference between brightness temperatures $(\Delta T)$ at $10.8\left(T_{10.8}\right)$ and $12 \mu \mathrm{m}\left(T_{12}\right)$ is often used to detect volcanic ash from space (Prata, 1989). For volcanic ash clouds $\Delta T$
$\left(=T_{10.8}-T_{12}\right)$ is negative in contrast to liquid-water and ice clouds, which give positive $\Delta T$. Assuming spherical ash particles composed of andesite and a monodisperse size distribution, Wen and Rose (1994) showed that the particle radius has to be below $5 \mu \mathrm{m}$ to give a negative $\Delta T$. This implies that for andesite the particles in a given size distribution (for example log-normal) that contribute to the negative $\Delta T$ have radii $<5 \mu \mathrm{m}$. The effective radius, defined as the ratio of the third and second moment of the size distribution, may be larger than $5 \mu \mathrm{m}$ depending on the form of the distribution. Effective radii $>5 \mu \mathrm{m}$ estimated from infrared (IR) satellite measurements have been reported by several authors (see for example Yu et al., 2002; Corradini et al., 2008; Francis et al., 2012; Pavolonis et al., 2013). For retrieval of ash mass loading and effective radius, it is common to assume that the ash particles are spherical and thus use Mie theory to calculate the optical properties (e.g. extinction cross section, single scattering albedo and asymmetry factor; Prata, 1989; Wen and Rose, 1994; Clarisse et al., 2010; Prata and Prata, 2012; Pavolonis et al., 2013). It is well established that, over a large range of radii, wavelengths, and dielectric properties, the optical properties of non-spherical particles can be significantly different from those of spherical particles (for a readable and general introduction into the vast field of scattering by nonspherical particles, we refer the reader to the recent review by Mishchenko, 2009). The non-sphericity of particles residing in the earth's atmosphere may affect the signal measured by satellites and as such have an impact on the quantity, which is being remotely sensed (e.g. the mass of a volcanic ash cloud). 
Krotkov et al. (1999) used randomly oriented spheroids to test the sensitivity of Total Ozone Mapping Spectrometer (TOMS) retrieval of ash cloud optical depth and effective radius. The TOMS observes backscattered solar radiation in the $0.34-0.38 \mu \mathrm{m}$ spectral interval. The assumption of spherical particles underestimates the effective radius by up to $30 \%$ and overestimates the optical depth by up to $25 \%$. The total mass of the ash cloud is underestimated by $5-20 \%$. The UV volcanic ash refractive index used in that study, $m=1.5-0.005 i$, is different from that found in the thermal infrared where both the real and imaginary parts of the refractive index are higher (e.g. $m=2.11-0.59 i$ at $10.8 \mu \mathrm{m}$ and $m=1.83-0.13 i$ at $12 \mu \mathrm{m}$ for andesite according to Pollack et al., 1973). If the material of the particles is optically hard (large real part) or strongly absorbing (large imaginary part), particularly the roughness of the particle, not considered by Krotkov et al. (1999), may play an important role for the optical properties (e.g. Kahnert et al., 2011, 2012). Also, TOMS measures solar radiation backscattered by the atmosphere and its constituents, while IR detectors, such as the Spinning Enhanced Visible and Infrared Imager (SEVIRI), the Moderate Resolution Imaging Spectroradiometer (MODIS), the Advanced Very High Resolution Radiometer (AVHRR), and the Infrared Atmospheric Sounding Interferometer (IASI), measure the radiation emitted by the earth's surface and atmosphere. Thus, the results in the UV may not be directly transferable to the thermal infrared.

In the IR the influence of particle shape has been investigated for mineral dust aerosol and polar stratospheric clouds. Hudson et al. (2008a, b) found that, for particles in the fine particle mode, radius $0.05-2 \mu \mathrm{m}$, ellipsoid particles and disk-shaped models better reproduced experimental mineral component IR spectra compared to Mie theory calculations for non-clay and clay components of mineral dust aerosol, respectively. Klüser et al. (2012) used these measured mineral component IR spectra, which include non-spherical effects and also variable mineral composition, in Infrared Atmospheric Sounder Interferometer (IASI) retrievals of desert dust aerosol optical depth, and found significant improvements in agreement with Aerosol Robotic Network (AERONET) observations. Similar shape effects in the infrared have earlier been shown for polar stratospheric clouds by Wagner et al. (2005).

To our knowledge only Newman et al. (2012) have investigated the effects of non-sphericity of volcanic ash particles in the infrared. They compared optical properties of equal volume spheres with those of randomly oriented hexagonal columns of aspect ratio unity as calculated by the Tmatrix method. Differences between the optical properties of the spheres and the hexagonal columns were reported to be less than $10 \%$, which was considered not significant for their purposes (lidar-derived aerosol extinction and ash mass concentration to be used in a radiative closure study). It is noted that Yang et al. (2007) have compared radiative properties of dust-like spheroids and spheres at thermal infrared wavelengths and concluded that the effect of nonsphericity was not significant. They based their conclusion on comparisons of brightness temperatures from simulations with spheres and spheroids and did not estimate the error on retrieved quantities.

Scanning-electron-microscope images of volcanic ash particles show the highly irregular shapes of the particles (see for example Riley et al., 2003; Muñoz et al., 2004; Schumann et al., 2011; Weber et al., 2012; Genareau et al., 2013). The shapes may be divided into three wide categories: vesicular, non-vesicular and miscellaneous shapes (Riley et al., 2003). Vesicular shapes may be present up to hundreds of kilometres from the volcano (Muñoz et al., 2004). For the Eyjafjallajökull 2010 eruption, vesicular shapes were present close to the volcano (about $50 \mathrm{~km}$ ), while non-vesicular shapes appeared to be dominant thousands of kilometres away from the vent (Schumann et al., 2011; Weber et al., 2012). The aim of the present study is to investigate how highly irregular and porous (vesicular) ash particles affect the thermal radiation measured by satellites and the possible impact on derived quantities such as ash mass loading. This is achieved by performing thermal infrared radiative transfer calculations with non-spherical ash particles and comparing with calculations using mass- and volume-equivalent spherical particles. The calculation of the optical properties of the ash particles, including description of their shapes, is outlined in Sect. 2. The radiative transfer setup and results are presented in Sect. 3. A discussion follows in Sect. 4 before conclusions are drawn.

\section{Calculation of ash particle optical properties}

To calculate the ash particle optical properties, model geometries for the ash particles are first generated. These geometries are then used in the single-scattering computations.

\subsection{Particle shapes}

Two distinct ash particle geometries are considered: vesicular ash particle shapes from Lindqvist et al. (2011) and porous spheroids from Nousiainen et al. (2011). The former model results in irregularly shaped particles, while in the latter the overall shape of the particles is spheroidal. Both types of particles are porous; that is, the generated model particles have hollow internal cavities.

In case of vesicular ash particles, we consider particles with both small and large vesicles (porous cavities). The generation of these shapes begins with a ballistic cluster of 40 (for large vesicles) or 500 (for small vesicles) spheres. The sizes of the spheres follow a power-law size distribution:

$n(r)=\frac{2 r_{\max } r_{\min }}{r_{\max }^{2}-r_{\min }^{2}} r^{-3}$,

where the maximum radius $r_{\max }=4.0 r_{\min }$ for large vesicles and $r_{\max }=2.0 r_{\min }$ for small vesicles. In the case of 
the large-vesicle particles, the ballistic clustering algorithm is modified to produce denser clusters such that, for every 10 spheres, only the sphere closest to the origin is chosen. After the cluster has been formed, it is enveloped in a concave surface by the concave-hull transformation (Lindqvist et al., 2009), where a generating sphere of radius $r_{\mathrm{g}}$ (for large vesicles $r_{\mathrm{g}}=0.5 r_{\max }$, and for small $r_{\mathrm{g}}=r_{\max }$ ) is rolled around the cluster, and the inner surface shaped by this sphere defines the enveloping concave hull. Then, each sphere in the cluster is replaced by a co-centred Gaussian random sphere. These are stochastic, statistically deformed spheres, which can be defined using, for example, a power-law index $v$ and a standard deviation of radial distance $\sigma$ (Muinonen et al., 2007). The values chosen for the ash particles are $\sigma=0.2$ and $v=4.0$. The space outside the Gaussian random spheres and inside the concave hull forms the ash particle, the Gaussian spheres defining the porous cavities. Since the Gaussian spheres are non-spherical, neighbouring Gaussian spheres may overlap, resulting in connected vesicles. To complete the ash particles, a shallow surface layer is removed from the particle so that some vesicles are exposed. The parameter values for these phenomenological model particles have been selected based on visually inspecting scanning-electron microscope images of real volcanic ash particles (Riley et al., 2003; Muñoz et al., 2004).

Porous spheroids have the shape of normal spheroids, but they are filled with spherical vesicles. Again, we consider model shapes with both large and small vesicles. The porous spheroids are generated as follows. First, a ballistic cluster of 150 spheres (large vesicles) or 500 spheres (small vesicles) is built. Again, the modified version of the ballistic cluster algorithm from Lindqvist et al. (2011) is used for a denser cluster. The sizes of the spheres vary according to the power-law size distribution in Eq. (1) with a maximum radius $r_{\max }=1.5 r_{\min }$. In case of large vesicles, both $r_{\max }$ and $r_{\min }$ are twice as large as in the case of small vesicles. Then, a spheroidal volume is overlaid, co-centred with the origin of the spherical cluster, and the interior of the spheroid is filled with material, except for the spheres. Everything outside the spheroidal volume is deleted. Four spheroids have been generated for the simulations: aspect ratio 1.5 prolate spheroid and aspect ratio 2.0 oblate spheroid, both with either small or large vesicles.

The porosity $p$ of a particle describes the fractional volume of the cavities within the particle. For the large-vesicle ash shapes, porosity varies between $p=0.41-0.60$ and, for small-vesicle ash, $p=0.29-0.31$. Both spheroids with small cavities have porosity $p=0.44$ while the porosity of largecavity spheroids is $p=0.48-0.50$.

In Fig. 1 the various ash particle shapes are presented. For further details of the model particle generation, we refer to the original publications by Lindqvist et al. (2011) and Nousiainen et al. (2011).
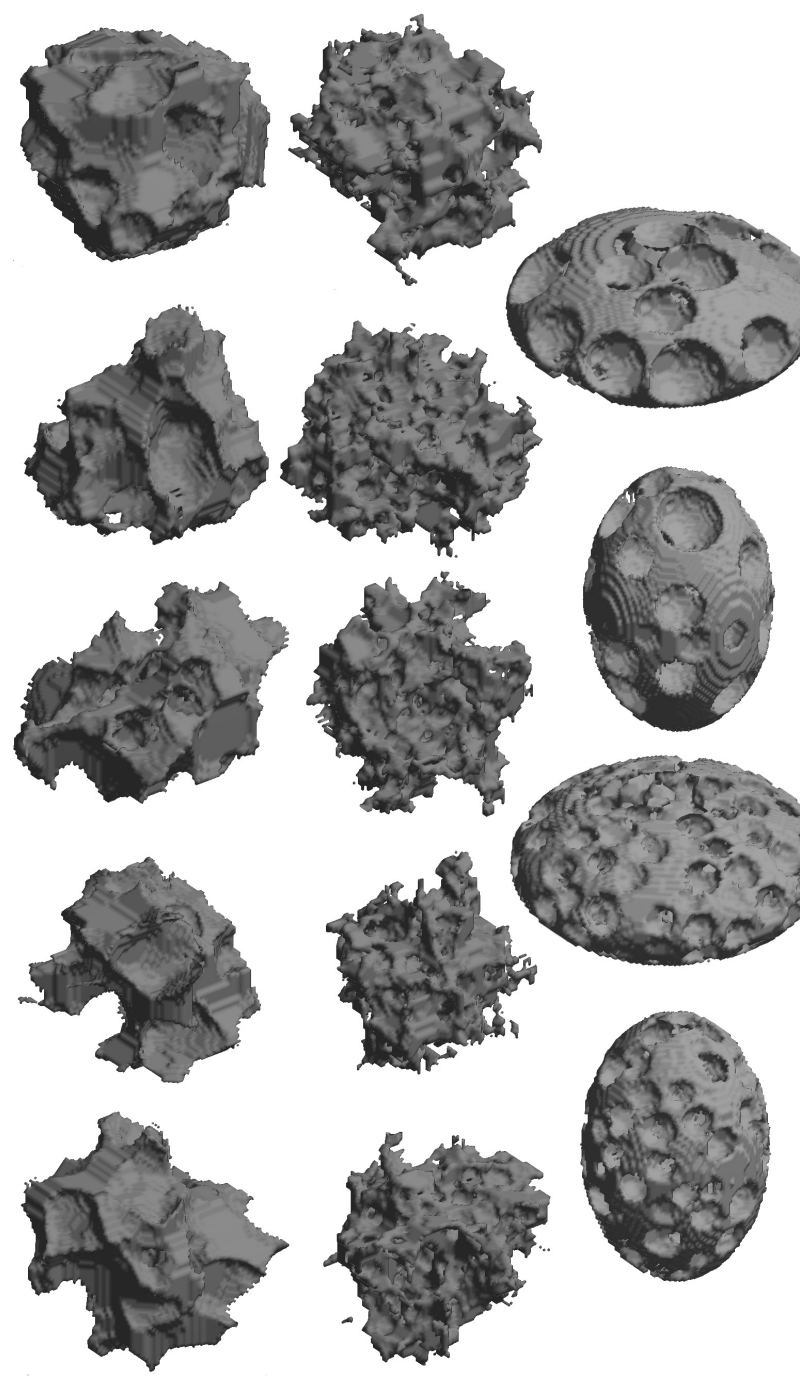

Fig. 1. Ash particles with large vesicles (left column), ash particles with small vesicles (middle column), prolate and oblate spheroids with large and small vesicles (right column).

\subsection{Single scattering optical properties}

The optical properties of the non-spherical ash particles were calculated by the discrete dipole approximation (DDA), using the DDSCAT programme (Draine and Flatau, 1994, 2012). The discrete dipole method is a volume-integral equation method, in which the volume integral is numerically evaluated by discretising the particle volume into (usually cubical) volume cells with side length $d$. The main assumption is that $d$ is sufficiently small so that the electric field can be assumed to be constant over each cell volume. Thus, the oscillators within each volume cell respond to the external field by oscillating in phase, just like a dipole, and phase differences may arise only between cells. This means that in the DDA the target is, essentially, replaced by an array of dipoles with a dipole spacing $d$. Calculations of the optical 
properties for the 14 geometries in Fig. 1 were made for 10 mass-equivalent radii of $1,2, \ldots, 10 \mu \mathrm{m}$, and for 2 IR wavelengths, 10.8 and $12 \mu \mathrm{m}$. The refractive index for andesite from Pollack et al. (1973) was used.

For comparison, computations for mass- and volumeequivalent spheres were performed with a standard Mie programme (Mishchenko et al., 2002). To compare these against the results based on non-spherical ash particles, the following two types of size equivalences were considered:

1. Mass-equivalent spheres with the same refractive index as andesite. In this case, the radius of the spheres was calculated from the andesite volume $V$ of the non-spherical particles given by $V=N d^{3}$, where $N$ is the number of andesite dipoles used to represent the target, and $d^{3}$ is the volume of each dipole cell. The dipoles within the gas pockets, vesicles, were excluded. The mass-equivalent radius $R_{\mathrm{m}}$ is obtained from $(4 / 3) \pi R_{\mathrm{m}}^{3}=N d^{3}$. It is noted that DDSCAT defines the extinction efficiency $Q_{\text {ext }}$ in terms of the extinction cross section $C_{\text {ext }}$ according to $Q_{\text {ext }}=$ $C_{\text {ext }} /\left(\pi R_{\mathrm{m}}^{2}\right)$, and similarly for the scattering efficiency $Q_{\text {sca. }}$.

2. Volume-equivalent spheres. Here, the total volume $V_{\text {tot }}$ of the particle (andesite and vesicles) was estimated, and the volume-equivalent radius $R_{\mathrm{V}}$ of the sphere defined by $(4 / 3) \pi R_{\mathrm{v}}^{3}=V_{\text {tot }}$. The volume-equivalent spheres were treated as a homogeneous mixture of andesite and gas pockets. We therefore needed to compute an effective refractive index of this mixture based on the andesite volume fraction. By considering all five stochastic realisations of each class of particles (small and large vesicles), the following average andesite volume fractions were obtained:

a. $50 \%$ for particles with large vesicles

b. $70 \%$ for particles with small vesicles.

The vesicles were assumed to be gas pockets with a refractive index of $m=1$. In each case an effective refractive index was calculated using

i. the Maxwell Garnett mixing rule (Maxwell Garnett, 1904)

ii. the Bruggeman mixing rule (Bruggeman, 1935).

The former treats the vesicles as inclusions in an andesite matrix, while the latter treats vesicles and andesite more symmetrically, assuming that both are inclusions in a matrix with an effective refractive index. More information on effective medium theories can be found in Chýlek et al. (2000) and references therein.

In Fig. 2 the extinction (first row) and scattering efficiencies (second row), single-scattering albedo (third row), and asymmetry parameter (fourth row) for wavelengths of
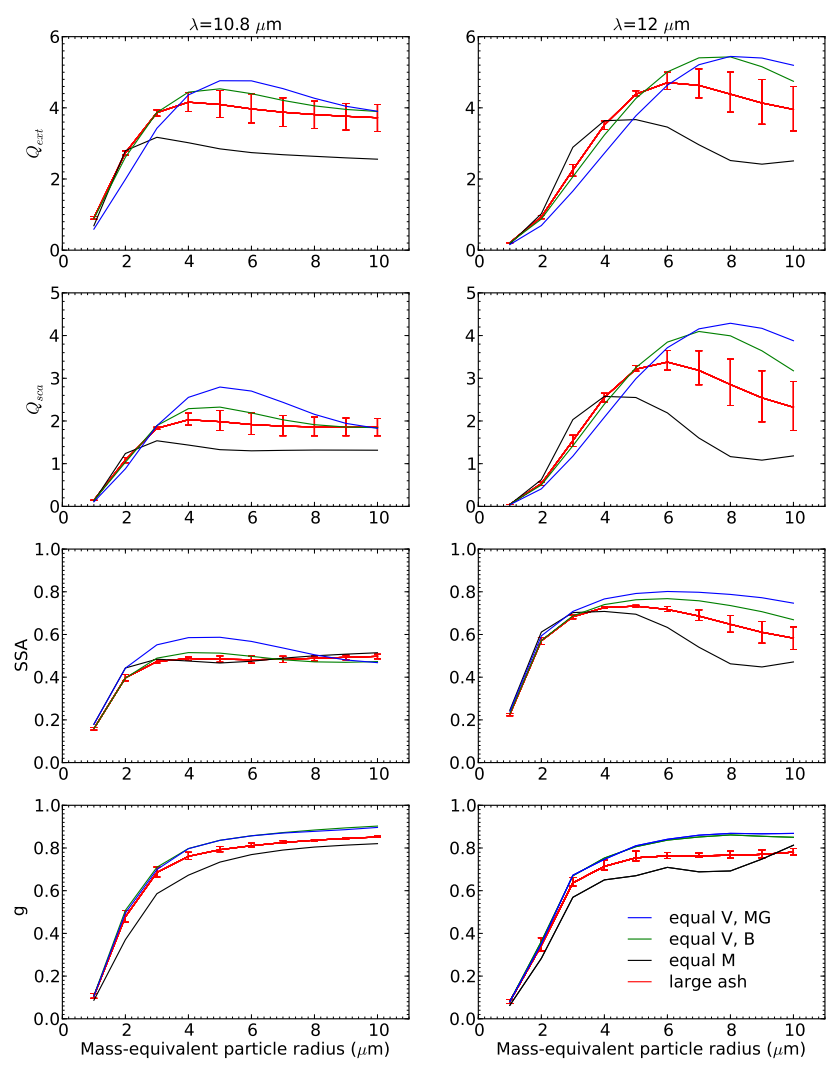

Fig. 2. Optical properties of large-vesicle ash particles and sphere models. The extinction (first row) and scattering efficiencies (second row), single-scattering albedo (third row), and asymmetry parameter (fourth row) are shown for wavelengths of $10.8 \mu \mathrm{m}$ (left column) and $12 \mu \mathrm{m}$ (right column). The mass-equivalent (equal M) spheres are shown in black, the volume-equivalent spheres using the Bruggeman mixing rule (equal V, B) in green and the volumeequivalent spheres using the Maxwell Garnett mixing rule (equal $\mathrm{V}, \mathrm{MG}$ ) in blue. The red lines represent the average of the nonspherical ash particles with the error bars representing the minimum and maximum values.

$10.8 \mu \mathrm{m}$ (left column) and $12 \mu \mathrm{m}$ (right column) of nonspherical ash particles with large vesicles are compared with mass- and volume-equivalent spherical particles. In Fig. 3 similar results are shown for non-spherical particles with small vesicles. The results for non-spherical ash particles (red lines) are represented as data points with error bars, where the central point indicates the average over the spheroids and the five realisations of ash particles, and the lower and upper end of the error bars indicate the minimum and maximum values within the particle ensembles. The various equivalent spheres are shown as black lines (mass-equivalent), blue lines (volume-equivalent/Maxwell Garnett), and green lines (volume-equivalent/Bruggeman). Note that we intentionally did not consider the case of volume-equivalent spheres having the same refractive index as the solid material (thus completely disregarding the presence of the vesicles). Such an ensemble of spheres would 

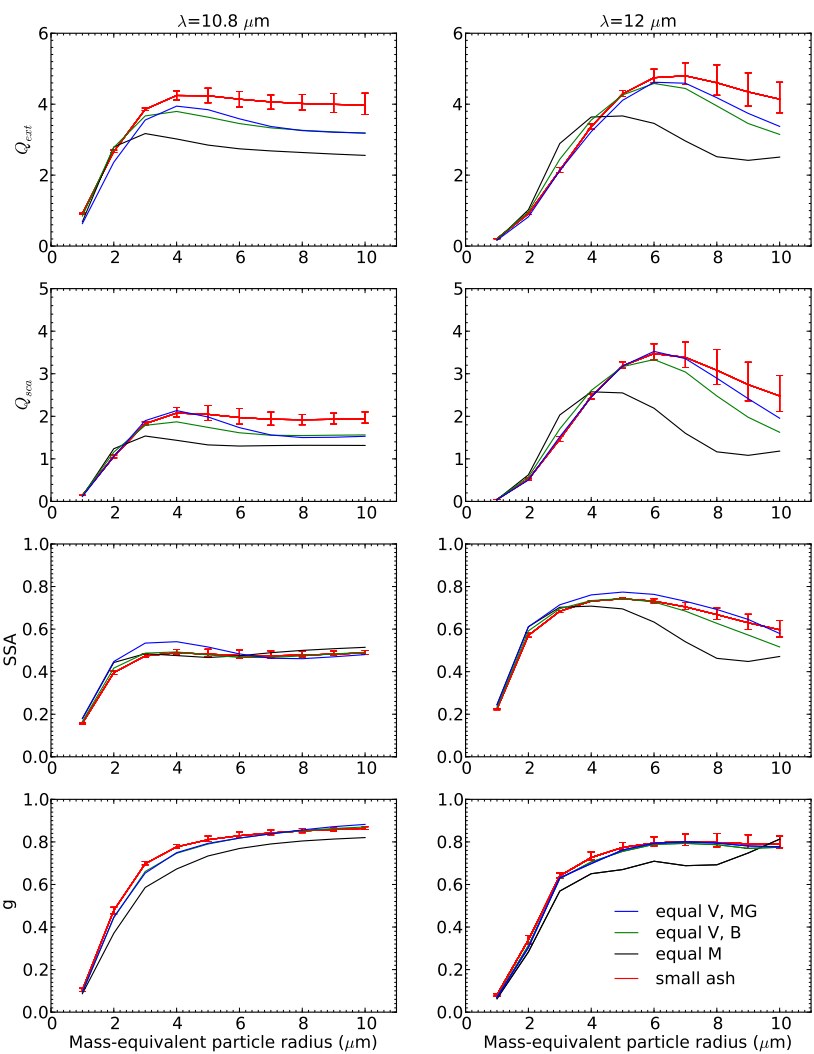

Fig. 3. Similar to Fig. 2 but for small-vesicle ash particles.

give optical properties with a size dependency very similar to that of mass-equivalent spheres (black lines Figs. 2 and 3) but with the lines squeezed towards smaller radii. In ash mass retrievals, such a model is likely to yield even larger differences compared to porous non-spherical ash particles than those introduced by the mass-equivalent sphere model.

For mass-equivalent particle radii below $3 \mu \mathrm{m}(4 \mu \mathrm{m})$, the optical properties of mass and volume-equivalent spheres behave similarly to those of non-spherical particles for a wavelength of $10.8 \mu \mathrm{m}(12.0 \mu \mathrm{m})$. For larger mass-equivalent particle radii, the optical properties calculated for mass- or volume-equivalent spheres do not generally agree with the optical properties of morphologically complex inhomogeneous ash particles. The mass-equivalent compact spheres (black lines Figs. 2-3) consistently underestimate the extinction and scattering efficiencies for mass-equivalent particle radii larger than 3 and $4-5 \mu \mathrm{m}$ for wavelengths of 10.8 and $12 \mu \mathrm{m}$ respectively, compared with both large- and small-vesicle non-spherical particles. The single scattering albedo is underestimated for $12.0 \mu \mathrm{m}$ but shows agreement for $10.8 \mu \mathrm{m}$. The mass-equivalent spheres generally underestimate the asymmetry factor. The performance of the two effective medium theories varies for mass-equivalent particle radii above 3-6 $\mu \mathrm{m}$ compared to the non-spherical particles. Both the volume-equivalent Maxwell Garnett and Bruggeman spheres overestimate the optical properties compared to large-vesicle non-spherical particles (Fig. 2). Compared to small-vesicle particles (Fig. 3), the volume-equivalent Maxwell Garnett and Bruggeman spheres somewhat underestimate the extinction and scattering efficiencies and show good agreement for the single scattering albedo and the asymmetry factor.

The asymmetry parameters are similar for each of the nonspherical ash model considered. For thermal radiation the source term in the radiative transfer equation does not include the phase function (Chandrasekhar, 1960). However, the phase function is of importance when scattering takes place, and, as shown in the third row of Figs. 2 and 3, the single scattering albedo is sufficiently large to make scattering effects have an impact for mass-equivalent particle radii larger than about $2 \mu \mathrm{m}$. For the calculations presented below multiple scattering is included for all particle radii.

For the non-spherical particles the differences between the various shapes increases with increasing mass-equivalent radius. The variation in the optical properties with shape is largest for the extinction and scattering efficiencies and significantly smaller for the single scattering albedo and the asymmetry parameter. The differences in the optical properties between non-spherical particles with large and small vesicles (red lines in Figs. 2 and 3) are small.

For a semi-transparent plane-parallel ash cloud for which scattering is assumed to be negligible, $\Delta T$ may be written as follows(Prata and Grant, 2001):

$\Delta T=\Delta T_{c}\left(X-X^{\beta}\right)$,

where $\Delta T_{\mathrm{c}}=T_{\mathrm{s}}-T_{\mathrm{c}}, X=1-\Delta_{10.8} / \Delta T_{\mathrm{c}}, \Delta_{10.8}=T_{\mathrm{s}}-T_{10.8}$, and $T_{\mathrm{S}}$ and $T_{\mathrm{c}}$ are the earth's surface and ash cloud temperatures, respectively. The ratio of the extinction coefficients is denoted by $\beta=k_{12} / k_{10.8}$. Normally we have $T_{\mathrm{s}}>T_{\mathrm{c}}$, and a value of $\beta>1$ will thus give negative $\Delta T$. The $\beta$ ratio is shown in Fig. 4 for all the various particles considered. It is larger than one for mass-equivalent spheres for mass-equivalent particle radii up to about $3.5 \mu \mathrm{m}$, whereas for the volume-equivalent spheres and non-spherical particles it is larger than one for mass-equivalent particle radius up to $4.5-6.5 \mu \mathrm{m}$. It is noted that the $\beta$ ratio for Bruggeman volume-equivalent spheres exhibits the same behaviour as for the non-spherical particles. There is also agreement between the non-spherical particles and the Maxwell Garnett volumeequivalent small-vesicle spheres for mass-equivalent radii larger than $3 \mu \mathrm{m}$. The $\beta$ ratio for Maxwell Garnett volumeequivalent large-vesicle spheres is overestimated for massequivalent radii between 3 and $7 \mu \mathrm{m}$ and underestimated elsewhere when compared to the non-spherical particles. Based on the simplified model Eq. (2), we thus expect that the nonspherical and the volume-equivalent spheres will result in negative $\Delta T$ for larger mass-equivalent particle radii than the mass-equivalent spheres. Below we investigate how the differences in the optical properties of the various particles affect the emitted infrared radiation from an ash cloud consisting of such particles. 


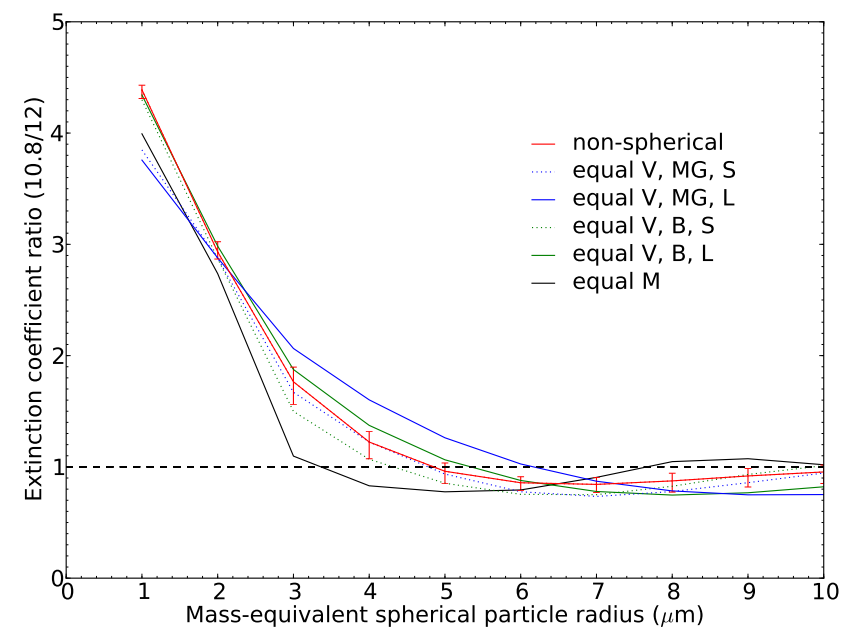

Fig. 4. The ratio of the extinction coefficients at 10.8 and $12.0 \mu \mathrm{m}$ for the various particle shapes. Mass-equivalent (equal $\mathrm{M}$ ) and volume-equivalent spheres (equal V) are shown. For the latter results for both Maxwell Garnett (MG) and Bruggeman (B), volumeequivalent spheres are shown for small (S) and large (L) vesicles. The red line represents the average of the non-spherical ash particles with the error bars representing the minimum and maximum values.

\section{Radiative transfer simulation setup and results}

To calculate the brightness temperature for satellite geometry, the libRadtran package was utilised (www.libradtran.org and Mayer and Kylling, 2005). The ash cloud was vertically homogeneous, $1 \mathrm{~km}$ thick, and with the cloud top at $10 \mathrm{~km}$. The subarctic summer atmosphere (Anderson et al., 1986) was adopted as the ambient atmosphere, thus giving a temperature of $225 \mathrm{~K}$ at $10 \mathrm{~km}$ and a surface temperature of $280 \mathrm{~K}$. The emissivity of the surface was set to 0.98 , which is representative of water at the wavelengths considered. Gaseous absorption was not included. Accurate treatment of the ash particle phase functions was assured by using the improved discrete-ordinate (DISORT) method by Buras et al. (2011), which is based on the versatile and much used DISORT algorithm by Stamnes et al. (1988). The improved DISORT code was run with 16 streams. A monodisperse particle size distribution was used. Brightness temperatures were calculated for wavelengths 10.8 and $12.0 \mu \mathrm{m}$ ( $T_{10.8}$ and $T_{12}$, respectively), representative of the central wavelengths for channels 9 and 10 of SEVIRI, for various ash optical depths and mass-equivalent particle radii.

In Fig. $5 T_{10.8}$ is shown versus the brightness temperature difference $\Delta T$ for a few representative particles shapes for nadir view. The solid lines in Fig. 5 represent various massequivalent particle radii whose values are indicated in black. The dotted blue lines indicate various ash optical depths whose values are given in blue.

The upper left plot is similar to those used to visualise the retrieval of ash mass loading and effective radius from $T_{10.8}$ and $T_{12}$ measurements under the assumption of spherical ash particles (Wen and Rose, 1994; Prata and Prata, 2012). The middle and lower left plots show results for the volumeequivalent large- and small-vesicle spheres, respectively, using the Bruggeman mixing rule. The results for the Bruggeman mixing rule volume-equivalent spheres are markedly different from those of the mass-equivalent spheres. For the mass-equivalent spheres, $\Delta T$ is negative for sizes smaller than $5 \mu \mathrm{m}$ in agreement with Wen and Rose (1994). For the volume-equivalent large- and small-vesicle particles with an effective refractive index based on Bruggeman effective medium theory, $\Delta T$ is negative for all particles and for particles smaller than about $8 \mu \mathrm{m}$, respectively. The right column in Fig. 5 shows $\Delta T$ versus $T_{10.8}$ for non-spherical ash particles with large-vesicle (upper plot) and small-vesicle (middle plot), and small-vesicle prolate spheroid particles (lower plot). The results for the other non-spherical shapes are similar. The non-spherical ash particles with large (upper right plot) and small (middle right plot) vesicles are qualitatively similar to the volume-equivalent large-vesicle particles (middle left plot). The prolate small-vesicle spheroids are qualitatively similar to the volume-equivalent small-vesicle particles (lower left plot).

To further visualise the differences between the various particles, $\Delta T$ is shown as a function of mass-equivalent particle radius for the various particle shapes and optical depths in Fig. 6. It is seen that the volume-equivalent spheres based on the Maxwell Garnett mixing rule give a slightly more negative $\Delta T$ compared to the Bruggeman spheres. The volume-equivalent spheres with small vesicles (dotted lines, Fig. 6) behave similarly to the non-spherical particles (red line, Fig. 6). This is consistent with the optical properties shown in Figs. 2 and 3. Volume-equivalent spheres with large vesicles (solid blue and green lines, Fig. 6) give larger negative $\Delta T$ for mass-equivalent radii larger than about $5 \mu \mathrm{m}$ compared to the non-spherical particles. The mass-equivalent spheres give less negative $\Delta T$ for mass-equivalent radii larger than about $3 \mu \mathrm{m}$ compared to the non-spherical particles. The volume-equivalent spheres with large vesicles do not give positive $\Delta T$ for any mass-equivalent radii, whereas volume-equivalent spheres with small vesicles give positive $\Delta T$ for radii larger than about $7 \mu \mathrm{m}(9 \mu \mathrm{m})$ for the Bruggeman (Maxwell Garnett) mixing rule.

\section{Discussion}

Information about volcanic ash in the atmosphere from infrared measurements may be deduced in a two-step process. First, ash affected pixels are detected; secondly, the ash physical properties are retrieved from ash affected pixels.

The detection of ash by the reverse absorption technique is based on the different spectral behaviour of the extinction coefficients of volcanic ash, liquid-water and ice clouds and the trace gases in the atmosphere (Prata, 1989). A negative $\Delta T$ 

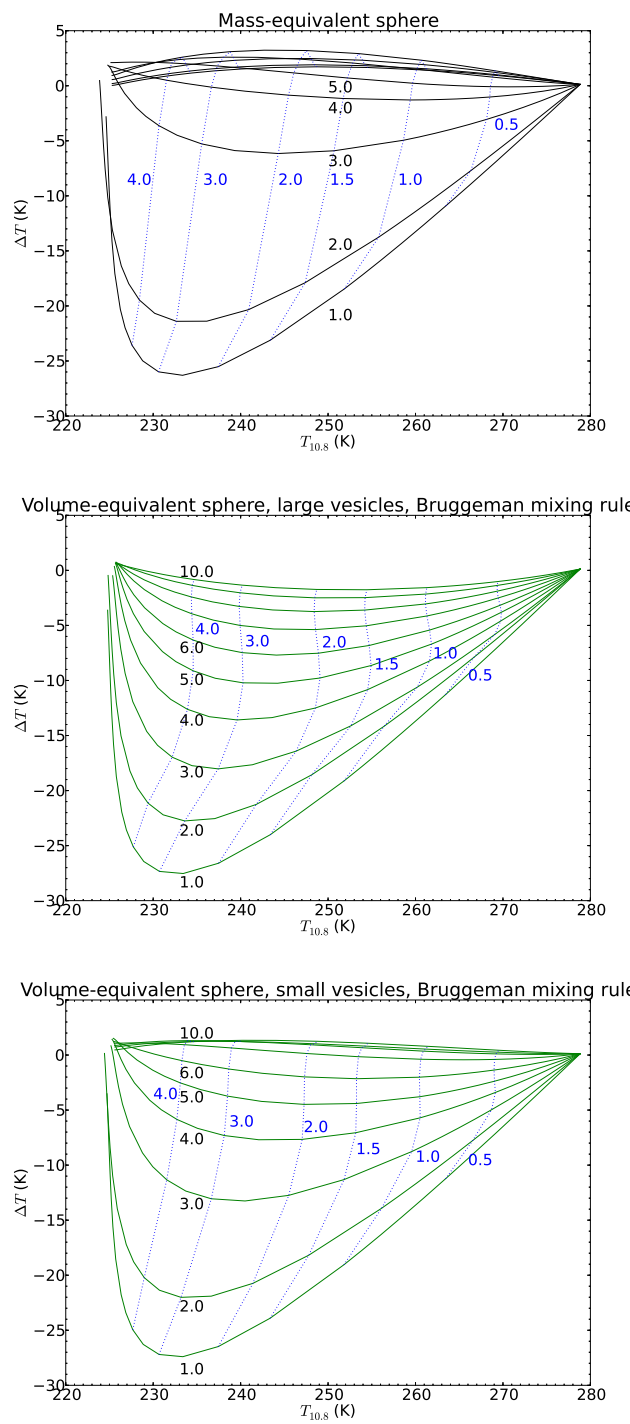
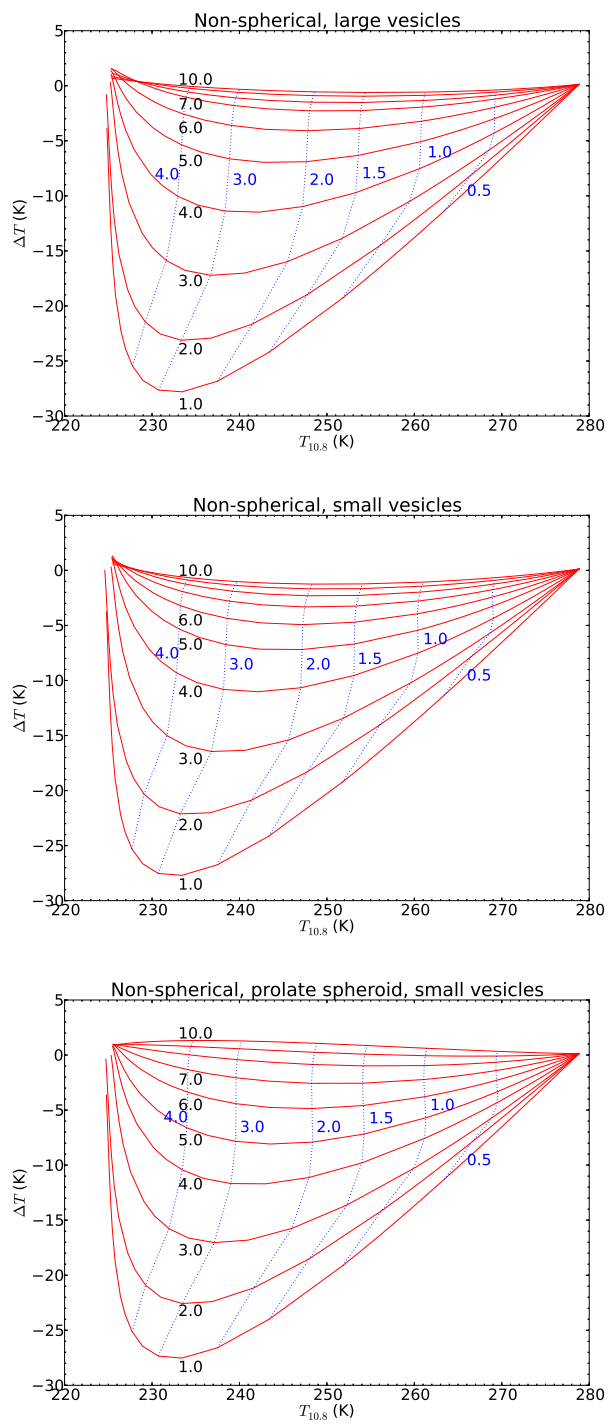

Fig. 5. The brightness temperature $\left(T_{10.8}\right)$ at $10.8 \mu \mathrm{m}$ versus the brightness temperature difference $(\Delta T)$ for various model ash particle types. Black coloured numbers label mass-equivalent particle radius $(\mu \mathrm{m})$ isolines (solid lines). Blue numbers are ash cloud optical depth (dotted blue lines).

indicates volcanic ash, whereas liquid-water and ice clouds give positive $\Delta T$. The non-spherical ash particles in this study give negative $\Delta T$ for a wider range of particle sizes than mass-equivalent spherical particles (Figs. 4-6). Thus, assuming that the non-spherical particles are a better representation of the real world compared to mass-equivalent spherical particles, nature produces negative $\Delta T$ for a larger size range than modelled spherical particles.

The mass loading of a pixel may be calculated as (assuming monodispersed particles; Wen and Rose, 1994; Prata and Prata, 2012)

$m_{1}=\frac{4}{3} \rho \frac{r_{\mathrm{e}} \tau(\lambda)}{Q_{\mathrm{ext}}\left(\lambda, r_{\mathrm{e}}\right)}$ where the ash density $\rho=2600 \mathrm{~kg} \mathrm{~m}^{-3}$ and $\tau$ is the optical depth at wavelength $\lambda$. For a given combination of $\Delta T$ and $T_{10.8}$, the optical depth and effective radius $\left(r_{\mathrm{e}}\right)$ may be found from charts similar to those shown in Fig. 5. Usually massequivalent spheres, upper left plot, are used for retrieval of ash optical properties. The use of any of the other ash particle shapes will give a different ash mass loading.

In the left plot of Fig. 7 is shown the ash mass loading retrieved from SEVIRI 10.8 and $12.0 \mu \mathrm{m}$ channel measurements for a case during the Eyjafjallajökull 2010 eruption. The retrieval was made using an optimal estimation technique (Kylling, 2014), and non-spherical ash particles with large vesicles were assumed. Furthermore, a monodisperse size distribution was used. For comparison retrievals were also made assuming mass-equivalent spheres. The difference 

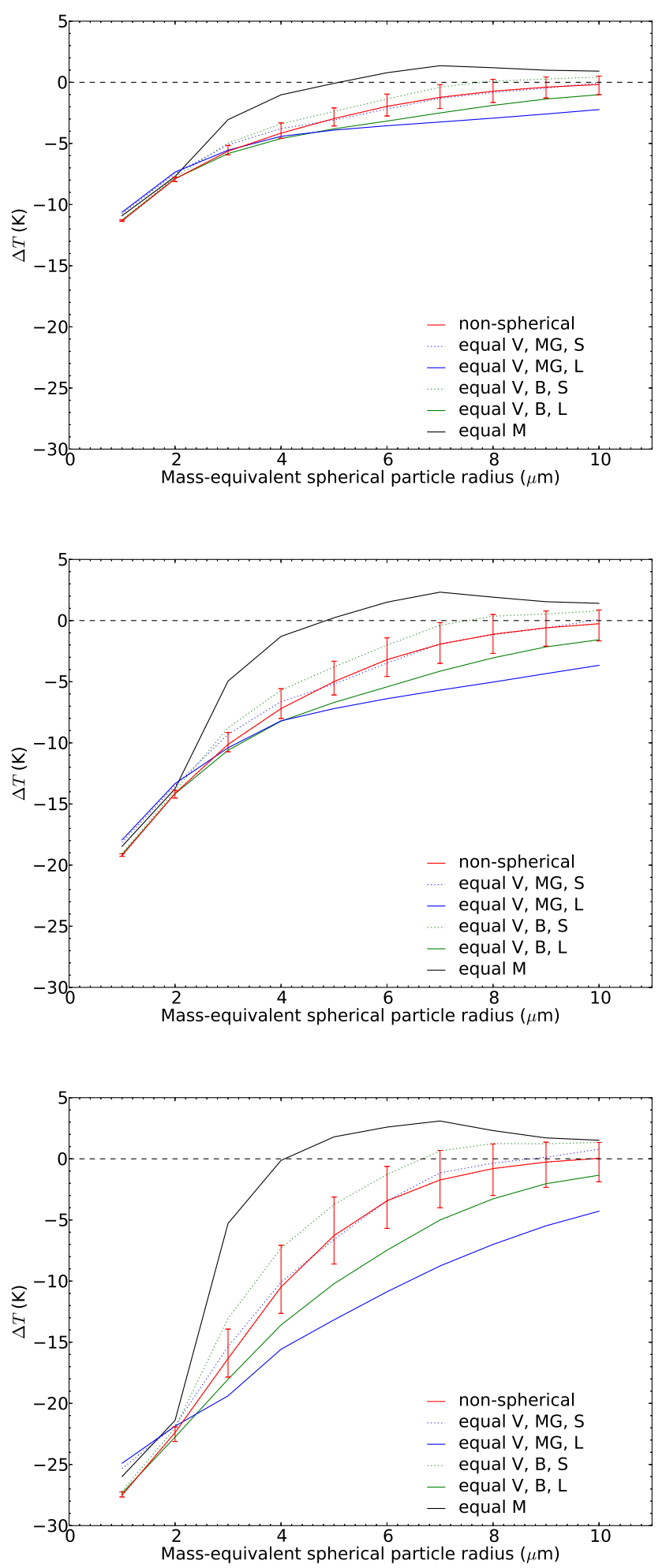

Fig. 6. The brightness temperature difference as a function of particle size for ash cloud optical depths of 0.5 (top), 1.0 (middle) and 3.0 (bottom). For explanation of legends see Fig. 4. between the ash mass loading when using the two types of model particles is shown in the right plot of Fig. 7. For all pixels the non-spherical particles give a larger ash mass loading compared to the mass-equivalent spheres. The difference in ash mass loading is plotted as a function of the mass loading for non-spherical particles in Fig. 8. The difference between the ash mass loadings from the two different particle types is seen to increase nearly linearly with mass loading.

The uncertainty in the total mass of the ash cloud due to the assumption of particle shape and the treatment of porosity may be compared with the uncertainties in total mass arising from the lack of knowledge in other contributing factors (surface temperature, surface emissivity, plume geometry and altitude, aerosol type, atmospheric water vapour). Corradini et al. (2008) have estimated that typical uncertainty in total mass estimates due to these other factors is of the order of $40 \%$. The total mass for the case in Fig. 7 retrieved with nonspherical ash model particles (mass-equivalent spheres) is $3.47 \times 10^{8} \mathrm{~kg}\left(2.48 \times 10^{8} \mathrm{~kg}\right)$. Mass-equivalent spheres thus underestimate the total mass by about $30 \%$. The particle shape is thus as important as the other previously considered factors. Assuming independent uncertainties the total uncertainty in the total mass is given by the square root of the sum of the squared uncertainties. Adding the uncertainty due to shape to the other sources of uncertainty, the uncertainty of the total mass increases from $40 \%$ to about $50 \%$.

\section{Conclusions}

Optical properties have been calculated for highly irregular and porous ash particles with refractive indices relevant for the thermal infrared. Brightness temperatures at 10.8 and $12 \mu \mathrm{m}$ as measured by an earth-viewing satellite have been calculated for irregular and porous ash particles, and massand volume-equivalent spheres. The following was found:

1. Optical properties of non-spherical particles differ significantly from mass-equivalent spherical particles for mass-equivalent radii $>3 \mu \mathrm{m}(4 \mu \mathrm{m})$ at $10.8 \mu \mathrm{m}$ $(12.0 \mu \mathrm{m})$.

2. Optical properties of non-spherical large (small) vesicle particles differ significantly from volumeequivalent spherical large (small) vesicle particles for mass-equivalent radii $>6 \mu \mathrm{m}(4 \mu \mathrm{m})$ at $12.0 \mu \mathrm{m}$. At $10.8 \mu \mathrm{m}$ the differences are smaller.

3. Mass-equivalent spherical particles produce a negative $\Delta T$ for a narrower particle size range (up to $5 \mu \mathrm{m})$ than volume-equivalent spherical particles and non-spherical particles (up to $10 \mu \mathrm{m}$ ). This indicates that, assuming porous non-spherical particles are a better representation of ash particles, a wider range of ash particles is detectable by the inverse absorption technique method than indicated by spherical particle model calculations. 

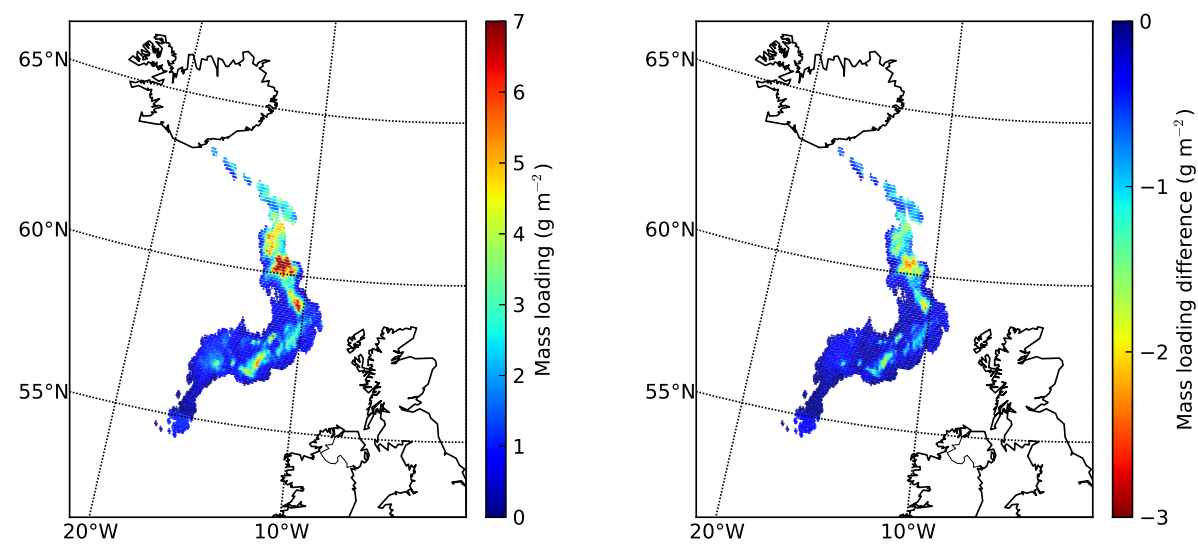

Fig. 7. Left: the ash mass loading for 19:00 UTC on 6 May 2010 during the Eyjafjallajökull eruption. The ash mass loading was derived assuming non-spherical ash particles with large vesicles. Right: the difference (= (spherical mass-equivalent spheres) - (non-spherical ash particles)) in ash mass loading between retrievals using mass-equivalent spheres and non-spherical ash particles with large vesicles.

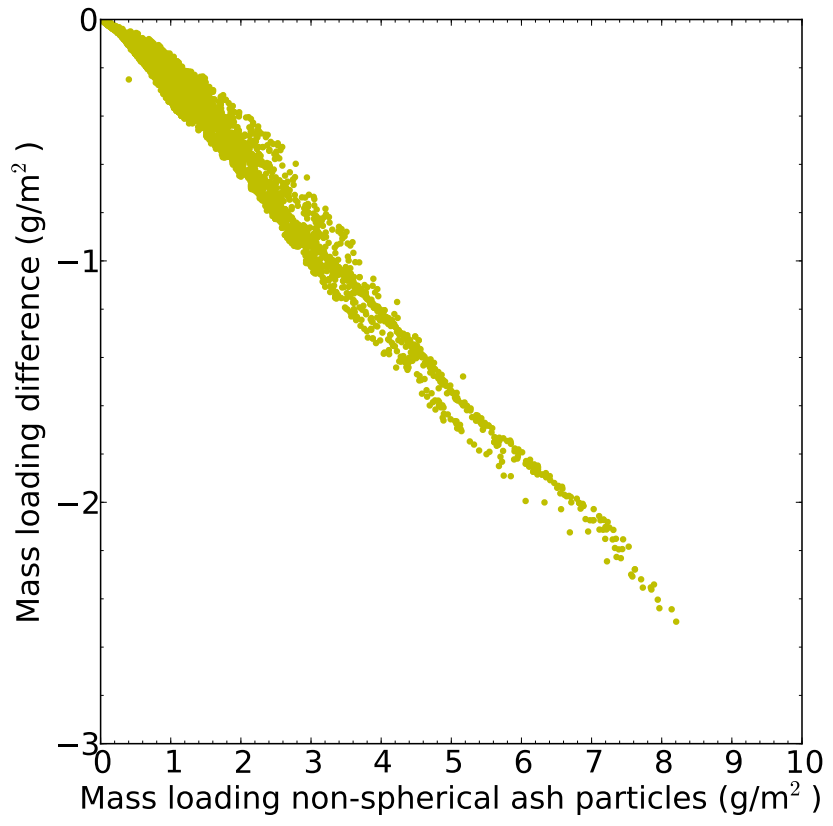

Fig. 8. Scatter plot of the ash mass loading for non-spherical ash particles versus the difference in mass loading between massequivalent spheres and non-spherical particles with large vesicles. Data are from the same case as in Fig. 7.

4. For ash mass loading retrieval, mass-equivalent spherical particles will underestimate the mass loading compared to non-spherical particles; the magnitude of the difference increases with the mass loading. The relative difference in the total mass of the analysed ash cloud is about $30 \%$.

5. The uncertainty due to particle shape increases the error in the total mass of the ash cloud from about $40 \%$ to about $50 \%$.
It is noted that ash particle shape is not usually known for an ongoing volcanic eruption. Thus, for operational monitoring of ongoing volcanic eruptions, it may be preferable to assume spherical ash particles and rather increase the uncertainty in the mass estimate.

Acknowledgements. B. Draine and M. Mishchenko are acknowledged for making their respective light scattering programmes publicly available. M. Kahnert acknowledges funding from the Swedish Research Council (Vetenskapsrådet) under project 6212011-3346. H. Lindqvist and T. Nousiainen acknowledge funding from the Academy of Finland. A. Kylling acknowledges support from the FP7 project FUTUREVOLC "A European volcanological supersite in Iceland: a monitoring system and network for the future" (grant agreement no. 308377) and the Norwegian Research Council (Contract 224716/E10). EUMETSAT is acknowledged for providing SEVIRI data via EUMETCast. Constructive comments from the anonymous referees are greatly appreciated.

Edited by: M. von Hobe

\section{References}

Anderson, G., Clough, S., Kneizys, F., Chetwynd, J., and Shettle, E.: AFGL atmospheric constituent profiles $(0-120 \mathrm{~km})$, Tech. Rep. AFGL-TR-86-0110, Air Force Geophys. Lab., Hanscom Air Force Base, Bedford, Mass., 1986.

Bruggeman, D. A. G.: Berechnung verschiedener physikalischer Konstanten von heterogenen Substanzen. 1. Dielektrizitätskonstanten und Leitfähigkeiten der Mischkörper aus isotropen Substanzen, Ann. Phys., 24, 636-664, 1935.

Buras, R., Dowling, T., and Emde, C.: New secondary-scattering correction in DISORT with increased efficiency for forward scattering, J. Quant. Spectrosc. Ra., 112, 2028-2034, doi:10.1016/j.jqsrt.2011.03.019, 2011.

Chandrasekhar, S.: Radiative Transfer, Dover, Mineola, N. Y., iSBN 0-486-60590-6, 1960. 
Chýlek, P., Videen, G., Geldart, D. J. W., Dobbie, J. S., and Tso, H. C. W.: Effective medium approximations for heterogeneous particles, in: Light scattering by nonspherical particles, edited by: Mishchenko, M. I., Hovenier, J. W., and Travis, L. D., 274-308, Academic Press, San Diego, 2000.

Clarisse, L., Hurtmans, D., Prata, A. J., Karagulian, F., Clerbaux, C., Maziére, M. D., and Coheur, P.-F.: Retrieving radius, concentration, optical depth, and mass of different types of aerosols from high-resolution infrared nadir spectra, Appl. Optics, 49, 37133722, 2010.

Corradini, S., Spinette, C., Carboni, E., Tirelli, C., Buongiorno, M. F., Pugnaghi, S., and Gangale, G.: Mt. Etna tropospheric ash retrieval and sensitivity analysis using Moderate Resolution Imaging Spectroradiometer Measurements, J. Appl. Remote Sens., 2, 023550, doi:10.1117/1.3046674, 2008.

Draine, B. T. and Flatau, P. J.: Discrete dipole approximation for scattering calculations, J. Opt. Soc. Am., 11, 1491-1499, 1994.

Draine, B. T. and Flatau, P. J.: User Guide to the Discrete Dipole Approximation Code DDSCAT 7.2, available at: http://arXiv.org/ abs/1202.3424 (last access: 2 April 2014), 2012.

Francis, P. N., Cooke, M. C., and Saunders, R. W.: Retrieval of physical properties of volcanic ash using Meteosat: A case study from the 2010 Eyjafjallajökull eruption, J. Geophys. Res., 117, D00U09, doi:10.1029/2011JD016788, 2012.

Genareau, K., Mulukutla, G., Proussevitch, A., Durant, A., Rose, W., and Sahagian, D.: The size range of bubbles that produce ash during explosive volcanic eruptions, J. Appl. Volcanol., 2, 4, doi:10.1186/2191-5040-2-4, 2013.

Hudson, P. K., Gibson, E. R., Young, M. A., Kleiber, P. D., and Grassian, V. H.: Coupled infrared extinction and size distribution measurements for several clay components of mineral dust aerosol, J. Geophys. Res.-Atmos., 113, D01201, doi:10.1029/2007JD008791, 2008a.

Hudson, P. K., Young, M. A., Kleiber, P. D., and Grassian, V. H.: Coupled infrared extinction spectra and size distribution measurements for several non-clay components of mineral dust aerosol (quartz, calcite, and dolomite), Atmos. Environ., 42, 5991-5999, doi:10.1016/j.atmosenv.2008.03.046, 2008b.

Kahnert, M., Nousiainen, T., and Mauno, P.: On the impact of nonsphericity and small-scale surface roughness on the optical properties of hematite aerosols, J. Quant. Spectrosc. Ra., 112, 18151824,2011

Kahnert, M., Nousiainen, T., Thomas, M. A., and Tyynelä, J.: Light scattering by particles with small-scale surface roughness: comparison of four classes of model geometries, J. Quant. Spectrosc. Ra., 113, 2356-2367, 2012

Klüser, L., Kleiber, P., Holzer-Popp, T., and Grassian, V.: Desert dust observation from space - Application of measured mineral component infrared extinction spectra, Atmos. Environ., 54, 419-427, doi:10.1016/j.atmosenv.2012.02.011, 2012.

Krotkov, N., Flittner, D., Krueger, A., Kostinski, A., Riley, C., Rose, W., and Torres, O.: Effect of particle non-sphericity on satellite monitoring of drifting volcanic ash clouds, J. Quant. Spectrosc. Ra., 63, 613-630, doi:10.1016/S0022-4073(99)00041-2, 1999.

Kylling, A.: Impact of meteorological clouds on detection and retrieval of volcanic ash during the Eyjafjallajökull 2010 eruption: A modelling study, in preparation, 2014.
Lindqvist, H., Muinonen, K., and Nousiainen, T.: Light scattering by coated Gaussian and aggregate particles, J. Quant. Spectrosc. Ra., 110, 1398-1410, 2009.

Lindqvist, H., Nousiainen, T., Zubko, E., and Muñoz, O.: Optical modeling of vesicular volcanic ash particles, J. Quant. Spectrosc. Ra., 112, 1871-1880, doi:10.1016/j.jqsrt.2011.01.032, 2011.

Maxwell Garnett, J. C.: Colours in metal glasses and in metallic films, Philos. T. Roy. Soc. A, 203, 385-420, 1904.

Mayer, B. and Kylling, A.: Technical note: The libRadtran software package for radiative transfer calculations - description and examples of use, Atmos. Chem. Phys., 5, 1855-1877, doi:10.5194/acp-5-1855-2005, 2005.

Mishchenko, M. I.: Electromagnetic scattering by nonspherical particles: A tutorial review, J. Quant. Spectrosc. Ra., 110, 808-832, 2009.

Mishchenko, M. I., Travis, L. D., and Lacis, A. A.: Scattering, absorption, and emission of light by small particles, Cambridge University Press, Cambridge, 2002.

Muinonen, K., Zubko, E., Tyynelä, J., Shkuratov, Y. G., and Videen, G.: Light scattering by Gaussian random particles with discretedipole approximation, J. Quant. Spectrosc. Ra., 106, 360-377, 2007.

Muñoz, O., Vollen, H., Hovenier, J. W., Veihelmann, B., van der Zande, W. J., Waters, L. B. F. M., and Rose, W. I.: Scattering matrices of volcanic ash particles of Mount St. Helens, Redoubt, and Mount Spurr volcanoes, J. Geophys. Res., 109, D16201, doi:10.1029/2004JD004684, 2004.

Newman, S. M., Clarisse, L., Hurtmans, D., Marenco, F., Johnson, B., Turnbull, K., Havemann, S., Baran, A. J., O'Sullivan, D., and Haywood, J.: A case study of observations of volcanic ash from the Eyjafjallajökull eruption: 2. Airborne and satellite radiative measurements, J. Geophys. Res., 117, D00U13, doi:10.1029/2011JD016780, 2012.

Nousiainen, T., Kahnert, M., and Lindqvist, H.: Can particle shape information be retrieved from light-scattering observations using spheroidal model particles?, J. Quant. Spectrosc. Ra., 112, 22132225, doi:10.1016/j.jqsrt.2011.05.008, 2011.

Pavolonis, M. J., Heidinger, A. K., and Sieglaff, J.: Automated retrievals of volcanic ash and dust cloud properties from upwelling infrared measurements, J. Geophys. Res., 118, 1-23, doi:10.1002/jgrd.50173, 2013.

Pollack, J. B., Toon, O. B., and Khare, B. N.: Optical properties of some terrestrial rocks and glasses, ICARUS, 19, 372-389, 1973.

Prata, A. J.: Infrared radiative transfer calculations for volcanic ash clouds, Geophys. Res. Lett., 16, 1293-1296, 1989.

Prata, A. J. and Grant, I. F.: Retrieval of microphysical and morphological properties of volcanic ash plumes from satellite data: Application to Mt Ruapehu, New Zealand, Q. J. Roy. Meteorol. Soc., 127, 2153-2179, 2001.

Prata, A. J. and Prata, A. T.: Eyjafjallajökull volcanic ash concentrations determined using Spin Enhanced Visible and Infrared Imager measurements, J. Geophys. Res., 117, D00U23, doi:10.1029/2011JD016800, 2012.

Riley, C. M., Rose, W. I., and Bluth, G. J. S.: Quantitative shape measurements of distal volcanic ash, J. Geophys. Res.-Sol. Ea., 108, 2504, doi:10.1029/2001JB000818, 2003.

Schumann, U., Weinzierl, B., Reitebuch, O., Schlager, H., Minikin, A., Forster, C., Baumann, R., Sailer, T., Graf, K., Mannstein, H., Voigt, C., Rahm, S., Simmet, R., Scheibe, M., Lichtenstern, M., 
Stock, P., Rüba, H., Schäuble, D., Tafferner, A., Rautenhaus, M., Gerz, T., Ziereis, H., Krautstrunk, M., Mallaun, C., Gayet, J.F., Lieke, K., Kandler, K., Ebert, M., Weinbruch, S., Stohl, A., Gasteiger, J., Groß, S., Freudenthaler, V., Wiegner, M., Ansmann, A., Tesche, M., Olafsson, H., and Sturm, K.: Airborne observations of the Eyjafjalla volcano ash cloud over Europe during air space closure in April and May 2010, Atmos. Chem. Phys., 11, 2245-2279, doi:10.5194/acp-11-2245-2011, 2011.

Stamnes, K., Tsay, S.-C., Wiscombe, W., and Jayaweera, K.: Numerically stable algorithm for discrete-ordinate-method radiative transfer in multiple scattering and emitting layered media, Appl. Optics, 27, 2502-2509, 1988.

Wagner, R., Möhler, O., Saathoff, H., Stetzer, O., and Schurath, U.: Infrared Spectrum of Nitric Acid Dihydrate: Influence of Particle Shape, J. Phys. Chem. A, 109, 2572-2581, doi:10.1021/jp044997u, 2005.

Weber, K., Eliasson, J., Vogel, A., Fischer, C., Pohl, T., van Haren, G., Meier, M., Grobéty, B., and Dahmann, D.: Airborne insitu investigations of the Eyjafjallajökull volcanic ash plume on Iceland and over north-western Germany with light aircrafts and optical particle counters, Atmos. Environ., 48, 9-21, doi:10.1016/j.atmosenv.2011.10.030, 2012.
Wen, S. and Rose, W. I.: Retrieval of sizes and total masses of particles in volcanic clouds using AVHRR bands 4 and 5, J. Geophys. Res., 99, 5421-5431, 1994.

Yang, P., Feng, Q., Hong, G., Kattawar, G. W., Wiscombe, W. J., Mishchenko, M. I., Dubovik, O., Laszlo, I., and Sokolik, I. N.: Modeling of the scattering and radiative properties of nonspherical dust-like aerosols, J. Aerosol. Sci., 38, 995-1014, 2007.

Yu, T., Rose, W. I., and Prata, A. J.: Atmospheric correction for satellite-based volcanic ash mapping and retrievals using "split window" IR data from GOES and AVHRR, J. Geophys. Res., 107, AAC10.1-AAC10.19, doi:10.1029/2001JD000706, 2002. 